UDC 316.442:353.5

LBC 60.561.26:60.524.224.56

Submitted: 05.09.2019

Accepted: 18.10 .2019

\title{
TYPOLOGIZATION OF REGIONS OF THE RUSSIAN FEDERATION ON REASONS OF REFUSAL FROM USING ELECTRONIC GOVERNMENT SERVICES
}

\author{
Svetlana G. Bylina \\ Institute of Agrarian Problems of the Russian Academy of Sciences, Saratov, Russian Federation
}

\begin{abstract}
Today, the right choice of public policy mechanisms based on identifying pressing needs of users for realizing the economic, social and cultural benefits of introducing information and communication technology (ICT) tools when interacting with government bodies seems very relevant. However, regional differentiation of the level of development of information society requires the development of differentiated mechanisms for implementing electronic government projects. On the basis of the empirical analysis of regional features of objective reasons for the refusal by the rural population to use information and communication technology to get state and municipal services, a typology of the Russian regions for the share of the population that refused to use public services in electronic form for objective reasons is built. Based on the assessment of regression models, including indicators of the level of economic development of the regions, as well as the level of the ICT infrastructure development, factors that have the greatest influence on the objective reasons for the refusal of the rural population to use ICT tools to get state and municipal services for Russia as a whole and for different types of regions are identified. The paper establishes that the effectiveness of government measures to introduce e-government services and reduce the degree of differentiation of Russian regions on the use of this type of service depends on increasing investment in information and communication technologies, on reducing the cost of connecting and maintaining the ICT infrastructure for the rural population, as well as on the wide information work among the population about the benefits of using e-government services. It is also established that in terms of a sufficiently developed ICT infrastructure, the role of human capital is increasing in the number of factors influencing the objective reasons for non-use of the Internet to get state and municipal services.
\end{abstract}

Key words: information and communication technologies, electronic government, state and municipal services, rural population, typologization of regions.

Citation. Bylina S.G. Typologization of Regions of the Russian Federation on Reasons of Refusal From Using Electronic Government Services. Journal of Volgograd State University. Economics, 2020, vol. 22, no. 1, pp. 108-120. (in Russian). DOI: https://doi.org/10.15688/ek.jvolsu.2020.1.10

УДК $316.442: 353.5$

ББК 60.561.26:60.524.224.56

Дата поступления статьи: 05.09.2019

Дата принятия статьи: 18.10.2019

\section{ТИПОЛОГИЗАЦИЯ РЕГИОНОВ РОССИЙСКОЙ ФЕДЕРАЦИИ ПО ПРИЧИНАМ ОТКАЗА ОТ ИСПОЛЬЗОВАНИЯ УСЛУГ ЭЛЕКТРОННОГО ПРАВИТЕЛЬСТВА}

\footnotetext{
Светлана Геннадиевна Былина

Институт аграрных проблем РАН, г. Саратов, Российская Федерация

Аннотация. В настоящий момент весьма актуальным представляется верный выбор механизмов государственной политики на основе выявления насущных потребностей пользователей для реализации экономических, социальных и культурных преимуществ от внедрения средств информационно-коммуникационных технологий (далее - ИКТ) при взаимодействии с органами государственной власти. Однако региональная дифференциация уровня развития информационного общества требует разработки дифференцированных
} 
механизмов реализации проектов электронного правительства. На основе эмпирического анализа региональных особенностей объективных причин отказа от использования сельским населением средств ИКТ для получения государственных и муниципальных услуг построена типология регионов РФ по доле населения, отказавшегося от использования государственных услуг в электронном виде по объективным причинам. На основе оценки регрессионных моделей, включающих показатели уровня экономического развития регионов, а также уровня развития ИКТ-инфраструктуры и доступа, выявлены факторы, оказывающие наибольшее влияние на объективные причины отказа сельского населения от использования средств ИКТ для получения государственных и муниципальных услуг как для России в целом, так и для различных типов регионов. Установлено, что эффективности государственных мер по внедрению услуг электронного правительства и сокращению степени дифференциации регионов РФ по использованию данного вида услуг будет способствовать увеличение инвестиций на информационные и коммуникационные технологии, снижение затрат на подключение и обслуживание ИКТ-инфраструктуры для сельского населения, а также широкая информационная работа среди населения о преимуществах использования услуг электронного правительства. Определено, что при достаточно развитой ИКТ-инфраструктуре происходит усиление роли человеческого капитала в числе факторов, влияющих на объективные причины отказа от использования сети Интернет для получения государственных и муниципальных услуг.

Ключевые слова: информационно-коммуникационные технологии, электронное правительство, государственные и муниципальные услуги, сельское население, типологизация регионов.

Цитирование. Былина С. Г. Типологизация регионов Российской Федерации по причинам отказа от использования услуг электронного правительства // Вестник Волгоградского государственного университета. Экономика. - 2020. - Т. 22, № 1. - C. 108-120. - DOI: https://doi.org/10.15688/ek.jvolsu.2020.1.10

\section{Введение}

В условиях перехода России к информационному обществу существенно увеличивается роль информационных технологий в процессах государственного управления, его перестройки на основе учета интересов как конкретных граждан, так и общества в целом. Особая роль в данном процессе принадлежит электронному правительству, в основе идеи которого лежит «представление о государстве, как институте, призванном эффективно удовлетворять насущные потребности общества» [Быков, 2005, с. 69]. Перевод государственных услуг в электронный формат рассматривается Организацией Объединенных Наций в качестве одной из приоритетных целей формирования устойчивого и гибкого общества, осуществляемой как в развитых, так и в развивающихся странах мира [Исследование ООН ...].

В РФ институциональными основами формирования и развития электронного правительства являются Федеральные законы: «Об информации, информационных технологиях и о защите информации» № 149-Ф3 от 27.07.2006 г., «Об организации предоставления государственных и муниципальных услуг» № 210-Ф3 от 27.07.2010 г., «О персональных данных» № 152-Ф3 от 27.07.2006, «Об электронной подписи» № 63-Ф3 от 06.04.2011, госу- дарственные программы: «ФЦП Электронная Россия (2002-2010 годы)», «ГП Информационное общество (2011-2020 годы)», стратегические документы: «Концепция формирования в Российской Федерации электронного правительства до 2010 года», «Стратегия развития информационного общества в России», других нормативно-правовых актов. Понятие «электронное правительство» в Концепции определяется как «новая форма организации деятельности органов государственной власти, обеспечивающая за счет широкого применения информационно-коммуникационных технологий качественно новый уровень оперативности и удобства получения гражданами и организациями государственных услуг и информации о результатах деятельности государственных органов» [Концепция ...]. Одной из основных функций электронного правительства является предоставление государственных и муниципальных услуг гражданам и организациям в электронной форме. Приоритетная ориентация «на потребности пользователей всех категорий путем их постоянного изучения в различных жизненных и деловых ситуациях», а также «анализ текущих и будущих требований и ожиданий пользователей» [Системный проект ...] обозначены в качестве основных принципов развития и использования электронного правительства в Систем- 
ном проекте Электронного Правительства РФ, разработанного Министерством связи и массовых коммуникаций РФ, носящего концептуальный характер. Своевременное выявление насущных потребностей и верный выбор тех или иных механизмов государственной политики для реализации экономических, социальных и культурных преимуществ от внедрения новейших ИКТ при взаимодействии с органами государственной власти представляется в настоящий момент весьма актуальным.

В новой редакции Государственной программы «Информационное общество (20112020 гг.)» [Государственная программа ...], в качестве одного из индикаторов развития информационного общества отмечена доля граждан, использующая механизм получения государственных и муниципальных услуг в электронной форме, который к 2017 г. предполагается на уровне $60 \%$. Согласно данным Федерального статистического наблюдения по вопросам использования населением информационных технологий и информационно-телекоммуникационных сетей Росстата за 2017 год (далее ИКТ-2017) [Итоги ...] доля населения в возрасте 15-72 лет, использовавшего сеть Интернет для получения государственных и муниципальных услуг от численности всего населения соответствующего возраста составила $46,1 \%$ в городе и $30,6 \%$ - в селе. Значения того же показателя от численности населения указанного возраста, получившего государственные и муниципальные услуги: 67,7 \% - в городе, $52,2 \%$ - в селе. Таким образом, вопервых, очевидно недостижение поставленных в Государственной программе значений данного индикатора для сельского населения, во-вторых, существенная дифференциация между городским и сельским населением в использовании услуг электронного правительства.

Причины отказа населения от использования средств Интернета для получения государственных и муниципальных услуг, представленные в ИКТ-2017 [Итоги ...], можно условно разделить на две группы: объективные, которые зависят как от уровня развития ИКТинфраструктуры, так и степени разработанности, доступности, простоты использования вебсайтов, то есть лежащие в сфере регулирования государства, и субъективные, целиком зависящие от уровня развития человеческого капитала, степени восприятия инноваций и готовности населения к жизни и работе в информационном обществе. Структура причин отказа городского и сельского населения от использования сети Интернет для получения государственных и муниципальных услуг по данным за 2017 г. на основе данных ИКТ-2017 [Итоги ...] представлена на рисунке.

Необходимость личного визита и предоставление бумажных форм, а также недоступность услуги на веб-сайте свидетельствуют о технических недоработках, затрудняющих использование государственных услуг. Проблемы с электронной подписью и отсутствие немедленной реакции можно назвать условно объективными, так как здесь частично задействованы и субъективные моменты.

Очевидно, что у сельского населения несколько чаще возникали проблемы с электронной подписью и заметно чаще требовался личный визит и заполнение бумажных форм.

Различия в субъективном восприятии или невосприятии услуг электронного правительства между городским и сельским населением гораздо значительней. Заметно большая доля сельских жителей отмечает недостаток навыков и знаний. Однако сельчан меньше волнуют проблемы безопасности, у них меньше возможностей получить помощь профессионалов или людей, обладающих навыками работы со средствами ИКТ, и они менее склонны к личным визитам и персональным контактам при обращении за государственными или муниципальными услугами.

Уровень развития информационного общества и электронного правительства определяются совокупностью многих составляющих и имеют в нашей стране значительные различия не только между городом и селом, но и между регионами РФ. Так, расчеты по данным ИКТ-2017 [Итоги ...] показывают, что в Московской и Тюменской областях лишь 13,6 и $18,3 \%$ сельского населения, получившего госуслуги, не использовали сеть Интернет, в то время как в Чукотском автономном округе и Липецкой области доля данной части сельского населения составила 94,5 и 86,7 \% соответственно. Региональная дифференциация требует разработки дифференцированных механизмов реализации проектов электронного правительства. 


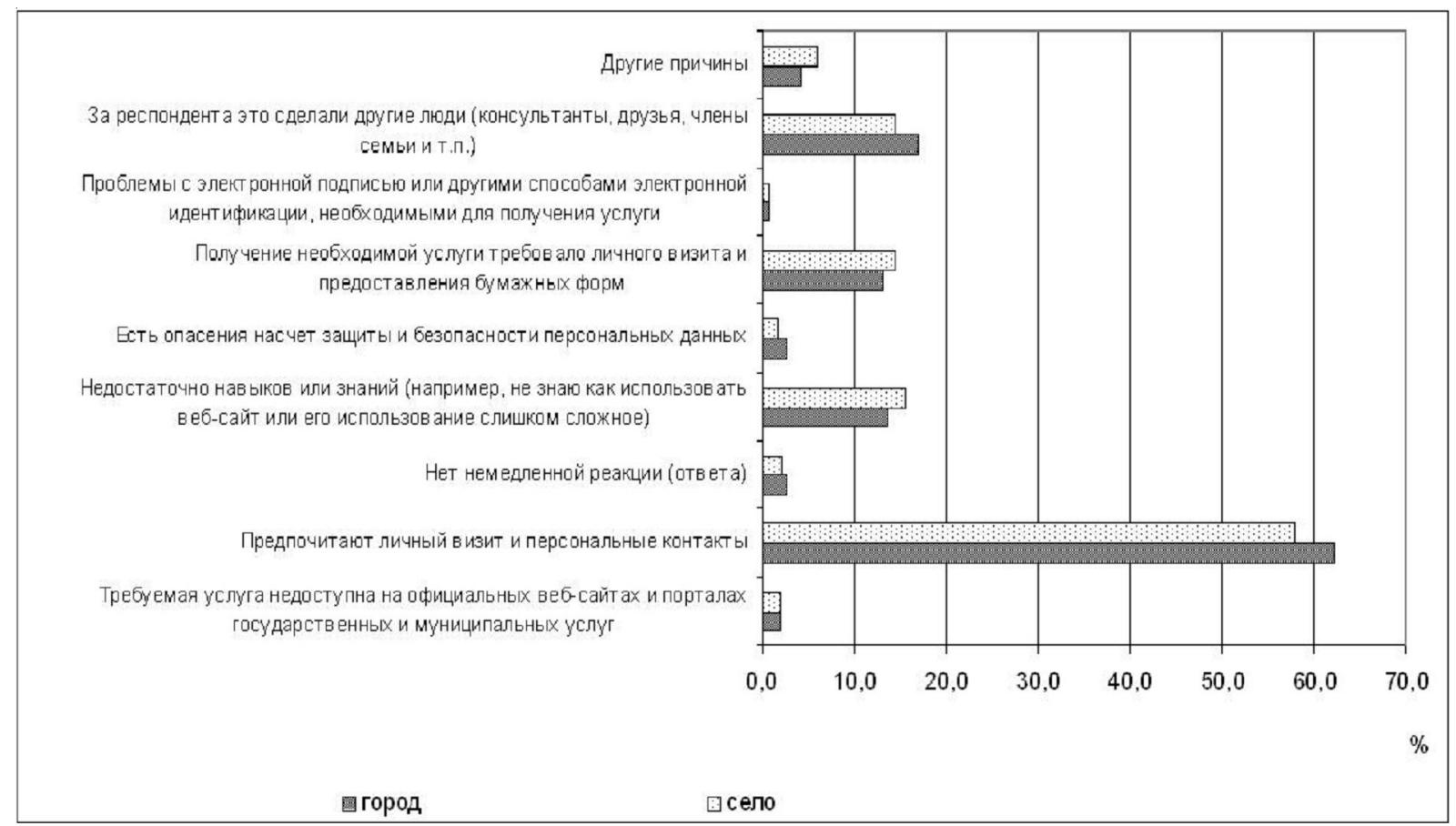

Рисунок. Структура причин отказа населения от использования средств ИКТ для получения государственных и муниципальных услуг *

Примечание. Составлено по: [Итоги ...]. * В \% от общей численности населения в возрасте 15-72 лет, не использовавшего сеть Интернет для получения государственных и муниципальных услуг, соответствующих групп в 2017 году.

Целью настоящего исследования является эмпирический анализ региональных особенностей объективных причин отказа от использования сельским населением средств ИКТ для получения государственных и муниципальных услуг, а также определение детерминант исследуемых параметров в регионах со сходными типообразующими признаками.

\section{Методика исследования}

Влияние различных факторов на использование или отказ от использования населением услуг электронного правительства исследовалось в основном зарубежными учеными с применением социологических и экономикоматематических методов.

Так, P. Chatzoglou, D. Chatzoudes, S. Symeonidis [Chatzoglou et al., 2015] с использованием статистических методов установили, что наиболее важными факторами, определяющими намерение использовать услуги электронного правительства, являются: воспринимаемая полезность, доверие, интернетопыт, влияние сверстников, компьютерная гра- мотность и предполагаемый риск. Исследователями I.-M. García-Sánchez, B. CuadradoBallesteros, J.-V. Frías-Aceituno [GarcíaSánchez et al., 2012] с использованием математических методов проанализированы факторы, способствующие развитию электронного управления в национальных правительствах 192 стран мира. Установлено существование двунаправленной связи между развитием электронного правительства и эффективностью управления. По мнению авторов, более высокий уровень развития электронного правительства тесно связан с внешними потребностями людей с более высоким уровнем грамотности, гораздо меньше - с уровнем технологического развития. Авторами Y. Al-Rahbi, S. Al-Harrasi, S. Al-Wahaibi [Al-Rahbi et al., 2012] рассмотрены технические факторы, которые влияют на реализацию успешного электронного правительства в Султанате Оман. Определено, что таковыми являются: инфраструктура ИКТ, информационная безопасность, стандарты информационных технологий и техническая экспертиза. Результаты исследований F. Belanger, L. Carter [Belanger et 
al., 2006] показывают, что доходы, образование, возраст и частота использования Интернета существенно влияют на использование услуг электронного правительства. R. Heeks [Heeks] на основании анализа причин провала электронных правительств в развивающихся странах делает вывод, что несоответствие между реальностью и архитектурой электронного правительства является главной причиной неудач. Автором обоснована необходимость создания технологической инфраструктуры, позволяющей всем гражданам иметь равный доступ к услугам электронного правительства.

Отечественные исследования, посвященные механизмам управления процессами развития и использования услуг электронного правительства с точки зрения привлечения пользователя, весьма фрагментарны. Так, С.Б. Шапошником [Шапошник, 2017] на основании статистических исследований 2003 2007 гг. сделан вывод о том, что доступ к ИКТ организаций и домохозяйств региона (обеспеченность компьютерами и доступом к сетям) определяется уровнем экономического развития региона и доходами домохозяйств, а реализация в регионе таких приложений, как электронная коммерция или электронное правительство, в большей степени зависит от уровня развития человеческого капитала. А.М. Степановой [Степанова, 2017] ставится вопрос о необходимости анализа целевой аудитории в целях привлечения пользователей при разработке информационной политики по популяризации электронного правительства. А.И. Ициксоном [Ициксон, 2018] исследована степень развития на сельских территориях доступа в Интернет и мобильных сетей как основы для использования различного рода услуг в электронном виде.

Настоящая работа является попыткой восполнить пробел в исследовании детерминант региональной дифференциации по причинам отказа от использования сельским населением средств ИКТ для получения государственных и муниципальных услуг и состоит из следующих этапов. На первом этапе построена типология регионов РФ по доле населения, не использовавшего сеть Интернет для получения государственных и муниципальных услуг по объективным причинам отка- за. Определены однородные группы регионов со сходными качественными признаками. На втором этапе исследования полученные классификационные группы рассмотрены в пространстве признаков, определяющих уровень экономического развития региона [валовой региональный продукт (далее - ВРП) на душу населения, величина среднедушевых денежных доходов], уровень развития ИКТ-инфраструктуры и доступа (затраты на информационные и коммуникационные технологии, рассчитанные на душу населения, удельный вес сельских домашних хозяйств, использующих сеть Интернет, имеющих: персональные компьютеры, широкополосный доступ к сети Интернет, мобильный доступ к сети Интернет), а также образовательную структуру сельского населения как одного из параметров качества человеческого капитала. Проведенный анализ послужил основой для выявления факторов, оказывающих наибольшее влияние на объективные причины отказа сельского населения от использования средств ИКТ для получения государственных и муниципальных услуг на основе оценки регрессионных моделей, включающих рассмотренные показатели, как для России в целом, так и для различных типов регионов.

Фактологической основой исследования послужили результаты Федерального статистического наблюдения по вопросам использования населением ИКТ-2017, а также данные официальных изданий Федеральной службы государственной статистики РФ [Регионы России ... , 2018; Российский ... , 2018; Информационное ..., 2018]. Факторный, кластерный, а также регрессионно-корреляционный анализы осуществлены в пакете статистической обработки данных STATISTICA 10. Исходные данные предварительно нормированы по формуле:

$$
X=\left(X_{i}-X_{\min }\right) / S \text {, }
$$

где $X_{\min }$ - минимальное значение параметра, $S$ стандартное отклонение.

Таким образом, все исходные значения параметров положительны, а их влияние на переменные сопоставимо по значениям коэффициентов регрессии. Все полученные моде- 
ли и коэффициенты при переменных значимы на 5 \% уровне и описывают от 52,3\% до 83,9\% вариации независимых переменных.

\section{Результаты и обсуждение}

В качестве типообразующих признаков при построении классификации взяты доли населения, отказавшегося от использования сети Интернет при получении государственных муниципальных услуг по следующим четырем причинам: требуемая услуга недоступна на официальных веб-сайтах и порталах государственных и муниципальных услуг; получение необходимой услуги требовало личного визита и предоставления бумажных форм; нет немедленной реакции (ответа); проблемы с электронной подписью или другими способами электронной идентификации, необходимыми для получения услуги. С использованием процедуры иерархического кластерного анализа построена классификация регионов РФ по выбранным признакам. Получено пять классификационных групп регионов со сходными качественными признаками. Состав групп представлен в таблице 1 , средние по группам значения типообразующих признаков в сравнении со средними значениями по РФ в целом - в таблице 2.

Таблииа 1

\section{Классификация регионов РФ по объективным причинам отказа от использования} сети Интернет для получения государственных и муниципальных услуг

\begin{tabular}{|c|c|l|}
\hline $\begin{array}{c}\text { Номер } \\
\text { группы }\end{array}$ & $\begin{array}{c}\text { Число } \\
\text { регионов }\end{array}$ & \multicolumn{1}{|c|}{ Состав групп } \\
\hline 1 & 17 & $\begin{array}{l}\text { Республики: Адыгея, Калмыкия, Карачаево-Черкесская, Карелия, Мордовия, Тыва. Кам- } \\
\text { чатский край. Области: Амурская, Архангельская, Волгоградская, Новгородская, Смолен- } \\
\text { ская, Саратовская, Тверская, Челябинская. Чукотский автономный округ. Еврейская авто- } \\
\text { номная область }\end{array}$ \\
\hline 2 & 18 & $\begin{array}{l}\text { Республики: Ингушетия, Кабардино-Балкарская, Коми, Северная Осетия - Алания, Татар- } \\
\text { стан, Чеченская. Края: Забайкальский, Краснодарский, Ставропольский, Хабаровский. Об- } \\
\text { ласти: Белгородская, Вологодская, Ленинградская, Оренбургская, Орловская, Пензенская, } \\
\text { Сахалинская. Ханты-Мансийский автономный округ }\end{array}$ \\
\hline 3 & 20 & $\begin{array}{l}\text { Республики: Алтай, Бурятия, Крым, Хакасия. Приморский край. Области: Брянская, Вла- } \\
\text { димирская, Калужская, Кемеровская, Кировская, Костромская, Магаданская, Нижегород- } \\
\text { ская, Ростовская, Тамбовская, Томская, Тульская, Тюменская, Ульяновская, Ярославская }\end{array}$ \\
\hline 4 & 14 & $\begin{array}{l}\text { Республики: Дагестан, Марий Эл. Края: Алтайский, Красноярский. Области: Воронежская, } \\
\text { Ивановская, Иркутская, Московская, Новосибирская, Псковская, Рязанская, Самарская. } \\
\text { Ненецкий и Ямало-Ненецкий автономные округа }\end{array}$ \\
\hline 5 & 13 & $\begin{array}{l}\text { Республики: Башкортостан, Саха (Якутия), Удмуртия, Чувашия. Пермский край. Области: } \\
\text { Астраханская, Калининградская, Курганская, Курская, Липецкая, Мурманская, Омская, } \\
\text { Свердловская }\end{array}$ \\
\hline
\end{tabular}

Примечание. Составлено автором.

Средние по классификационным группам доли населения, отказавшегося

Таблицьа 2 от использования сети Интернет для получения государственных услуг

\begin{tabular}{|c|c|c|c|c|}
\hline $\begin{array}{c}\text { Номер } \\
\text { группы }\end{array}$ & $\begin{array}{c}\text { Требуемая услуга недос- } \\
\text { тупна на официальных } \\
\text { веб-сайтах и порталах } \\
\text { государственных и му- } \\
\text { ниципальных услуг }\end{array}$ & $\begin{array}{c}\text { Получение необходимой } \\
\text { услуги требовало лично- } \\
\text { гозита и предоставле- } \\
\text { ния бумажных форм }\end{array}$ & $\begin{array}{c}\text { Нет немедленной реак- } \\
\text { ции (ответа) }\end{array}$ & $\begin{array}{c}\text { Проблемы с электронной } \\
\text { подписью или другими } \\
\text { способами электронной } \\
\text { идентификации, необхо- } \\
\text { димыми для получения } \\
\text { услуги }\end{array}$ \\
\hline $\mathbf{P \Phi}$ & $\mathbf{2 , 0}$ & $\mathbf{1 3 , 5}$ & $\mathbf{2 , 5}$ & $\mathbf{0 , 7}$ \\
\hline 1 & 3,9 & 18,8 & 2,8 & 1,3 \\
\hline 2 & 3,9 & 10,3 & 2,6 & 0,4 \\
\hline 3 & 1,2 & 24,2 & 2,2 & 1,1 \\
\hline 4 & 1,1 & 9,8 & 2,5 & \\
\hline
\end{tabular}

Примечание. Составлено автором. 
К первой классификационной группе отнесено 17 субъектов РФ, в каждом из которых значения двух первых типологических признаков (недоступность требуемой услуги на официальных веб-сайтах и необходимость личного визита при получении госуслуги) выше, чем в среднем по РФ. Доля населения, отказавшегося от сети Интернет при получении госуслуг по двум остальным рассмотренным причинам, также в среднем по группе выше среднероссийской. Отсутствие необходимой услуги на сайте госуслуг и необходимость личного предоставления бумажных форм лежат в сфере ответственности государственных структур и разработчиков онлайн-услуг. Пользователи могли бы воспользоваться ими, если бы была такая возможность. Особенно тяжела ситуация в Чукотском автономном округе, где доля населения, отказавшегося от онлайн-услуг по всем четырем причинам выше соответствующих средних значений по РФ в целом. В данном субъекте РФ максимальная по группе доля населения, отказавшегося от получения государственных услуг в электронной форме по причине их отсутствия на сайте госуслуг $(7,6 \%)$ и по причине отсутствия немедленной реакции (ответа) (15\%). В Новгородской области наибольшая по группе доля населения, отказавшегося от онлайн-госуслуг по причине необходимости личного визита и предоставления бумажных форм. Проблемы с электронной подписью стали причиной отказа максимальной по группе доли населения в республике Мордовия.

Первая классификационная группа характеризуется также в среднем невысокими значениями показателей, определяющих уровень экономического развития региона. Лишь в Камчатском крае и в Чукотском автономном округе величина ВРП на душу человека выше, чем в среднем по РФ. Величина среднедушевых денежных доходов в тех же регионах и Архангельской области выше среднероссийского значения. Уровень использования средств ИКТ сельским населением в регионах группы не слишком высок. Лишь доля сельских домохозяйств, имеющих выход в Интернет с мобильных устройств, выше, чем в среднем по РФ, остальные показатели ниже среднероссийских. В регионах группы выше среднероссийской относительная численность сельского населения со средним специальным образованием.

Результаты регрессионного анализа для классификационных групп регионов представлены в таблице 3.

Установлено, что для первой группы регионов фактором, оказывающим наибольшее влияние на отказ сельского населения от использования онлайн-госуслуг, является уровень среднедушевых денежных доходов населения.

Вторая классификационная группа состоит из 18 субъектов РФ и характеризуется выше средней по РФ долей населения, отказавшегося от использования сети Интернет при получении государственных и муниципальных услуг во всех регионах группы, и по причине отсутствия быстрого ответа - в подавляющем большинстве регионов (в 11 из 18). В среднем по группе также выше среднероссийской доля населения, имеющего проблемы с электронной подписью. Однако субъекты, отнесенные ко второй классификационной группе, отличаются ниже среднероссийской долей населения, отказавшейся от онлайн-госуслуг по причине необходимости личного визита и предоставления бумажных форм.

По уровню экономического развития регионы второй классификационной группы очень неоднородны. С одной стороны, в группу входят субъекты РФ с высоким значением ВРП на душу населения и среднедушевых денежных доходов, такие как: Ханты-Мансийский автономный округ, Хабаровский край, Сахалинская область. С другой стороны, республики Северного Кавказа, особенно Ингушетия и Чеченская с низкими значениями рассматриваемых показателей. Однако уровень использования сельскими домохозяйствами средств ИКТ весьма высок: вторая группа единственная, где все показатели наличия средств ИКТ у сельского населения выше среднероссийских. Вторая группа характеризуется также выше среднероссийской долей населения с высшим и средним специальным образованием.

Согласно результатам регрессионного моделирования (см. табл. 3) на снижение отказа от использования сети Интернет при получении госуслуг по причине необходимости 
предоставления бумажных форм и личного визита могут повлиять лишь увеличение затрат государства на ИКТ для перевода данного вида услуг в электронную форму. На все остальные причины отказа влияет обеспеченность сельского населения средствами ИКТ и, учитывая высокую относительную численность сельского населения с высшими уровнями образования, степень владения данными средствами для получения государственных услуг в электронном виде.

Третья группа самая многочисленная, содержит в своем составе 20 субъектов РФ, в каждом из которых доля населения, отказавшегося от онлайн-госуслуг по причине необходимости нанесения личного визита и предоставления бумажных форм, выше, чем в среднем по России. Особенно велики значения рассматриваемого показателя в Ульяновской $(51,8 \%)$ и Магаданской $(33,9 \%)$ областях, это максимальные значения по РФ в це- лом. По остальным рассматриваемым причинам отказа от использования сети Интернет при получении госуслуг доля населения ниже среднероссийской. Регионы группы отличаются низкими значениями показателей уровня экономического развития региона. Исключение составляют: Тюменская, Магаданская области и Приморский край. В подавляющем большинстве регионов третьей группы доля сельских домашних хозяйств, обладающих средствами ИКТ, ниже, чем в среднем по РФ. В третьей группе выше среднероссийской относительная численность сельского населения со средним специальным образованием.

Результаты регрессионного анализа показывают (табл. 3) влияние уровня экономического развития региона на отказ сельского населения от использования средств Интернета для получения государственных услуг. Доминирует также влияние роста затрат на

\section{Параметры регрессионных моделей по группам регионов РФ *}

Таблица 3

\begin{tabular}{|c|l|l|}
\hline $\begin{array}{c}\text { Номер } \\
\text { группы }\end{array}$ & \multicolumn{1}{|c|}{ Регрессионные зависимости } & $\begin{array}{c}\text { Коэффициент } \\
\text { множественной } \\
\text { детерминации }\end{array}$ \\
\hline 1 & $Y_{1}=1,853-0,621 X_{1}$, & $R^{2}=0,687$ \\
& $Y_{2}=0,072-1,282 X_{2}-0,045 X_{4}$, & $R^{2}=0,641$ \\
& $Y_{3}=0,252-1,811 X_{2}$, & $R^{2}=0,839$ \\
& $Y_{4}=3,505-0,703 X_{5}$ & $R^{2}=0,666$ \\
\hline 2 & $Y_{1}=3,419-0,607 X_{7}$ & $R^{2}=0,700$ \\
& $Y_{2}=1,258-0,930 X_{6}-0,976 X_{4}$ & $R^{2}=0,837$ \\
& $Y_{3}=1,426-0,907 X_{4}-0,567 X_{5}$ & $R^{2}=0,725$ \\
& $Y_{4}=4,769-1,565 X_{5}$ & $R^{2}=0,663$ \\
& $Y_{5}=0,973-0,195 X_{2}$ & $R^{2}=0,656$ \\
\hline 3 & $Y_{1}=2,506-0,456 X_{3}$ & $R^{2}=0,604$ \\
& $Y_{2}=0,208-0,228 X_{2}-0,198 X_{4}$ & $R^{2}=0,559$ \\
\hline 4 & $Y_{4}=0,032-0,260 X_{2}-0,267 X_{7}$ & $R^{2}=0,638$ \\
\hline & $Y_{1}=3,622-0,764 X_{6}$ & $R^{2}=0,602$ \\
\hline 5 & $Y_{5}=0,506-0,163 X_{2}-0,443 X_{5}-0,265 X_{6}$ & $R^{2}=0,618$ \\
& $Y_{1}=2,786+1,002 X_{1}-0,645 X_{7}$ & $R^{2}=0,521$ \\
\hline
\end{tabular}

Примечания. Составлено автором. * Принятые условные обозначения: $Y_{1}$ - удельный вес сельского населения, не использующего средства ИКТ для получения госуслуг; по причинам: $Y_{2}$ - требуемая услуга недоступна на официальных веб-сайтах и порталах государственных и муниципальных услуг; $Y_{3}-$ нет немедленной реакции (ответа); $Y_{4}$ - проблемы с электронной подписью или другими способами электронной идентификации, необходимыми для получения услуги; $Y_{5}-$ получение необходимой услуги требовало личного визита и предоставления бумажных форм; $X_{1}$ - размер среднедушевых денежных доходов; $X_{2}-$ затраты на информационные и коммуникационные технологии, приходящиеся на душу населения; $X_{3}-$ ВРП на душу населения; $X_{4}$-удельный вес домашних хозяйств, имеющих доступ к сети Интернет с мобильных устройств; $X_{5}-$ удельный вес домашних хозяйств, имеющих широкополосный доступ к сети Интернет; $X_{6}$ - удельный вес домашних хозяйств, имеющих персональные компьютеры; $X_{7}$ - удельный вес населения, когда-либо использовавшего сеть Интернет. 
информационные и коммуникационные технологии, на снижение уровня отказов от использования онлайн-госуслуг по причинам их недоступности на сайте или проблем с электронной подписью. Использование мобильных устройств, несомненно, может снизить долю отказов. Присутствие в модели, объясняющей изменение доли населения, отказавшегося от онлайн-госуслуг по причине наличия проблем с электронной подписью, показателя, характеризующего удельный вес населения, когдалибо использовавшего сеть Интернет, можно интерпретировать следующим образом. С одной стороны, это недостаток развития инфраструктуры и возможностей подключения к сети Интернет, с другой стороны, данный факт можно рассматривать с позиции уровня развития человеческого капитала, а именно информационно-когнитивного потенциала населения [Былина и др., 2018], уровня компьютерной грамотности, навыков работы со средствами ИКТ.

Четвертую классификационную группу регионов отличает лишь в среднем выше среднероссийской доля населения, отказавшегося от получения государственных услуг в электронном виде по причине проблем с электронной подписью. Во всех субъектах РФ, входящих в данную группу, доля населения с такими причинами отказа от получения онлайн-госуслуг, как недоступность услуги на официальных веб-сайтах и порталах государственных и муниципальных услуг, а также необходимость личного визита и предоставления бумажных форм, ниже средней по РФ. Регионы данной группы отличает в среднем высокий уровень экономического развития, показатели которого выше среднероссийских, хотя внутри группы регионы неоднородны. Так, в четвертую группу входят Ненецкий и Ямало-Ненецкий автономные округа, Московская область и Красноярский край с высокими показателями экономического развития. В то же время в республиках Марий Эл, Дагестан, Ивановской области данные показатели существенно ниже средних по РФ. Уровень обеспеченности домашних хозяйств весьма невысок и, за исключением удельного веса домашних хозяйств, имеющих персональные компьютеры, ниже, чем в регионах третьей классификационной группы.
Для регионов четвертой классификационной группы получены лишь две регрессионные модели, согласно которым компьютеризация домашних хозяйств может способствовать снижению доли отказов в использовании онлайн-госуслуг. В то же время необходимость личного визита и предоставление бумажных форм снизят свое значение в качестве причин отказа от онлайн-госуслуг при увеличении затрат на информационные и коммуникационные технологии, приходящихся на душу населения, и компьютеризации и росту доступа к широкополосному Интернету сельских домашних хозяйств.

Пятую классификационную группу регионов можно назвать относительно благополучной: доля населения, отказавшегося от использования государственных услуг в электронном виде по всем рассмотренным причинам отказа, во всех субъектах РФ, входящих в группу, ниже, чем в среднем по России. Уровень экономического развития в регионах третьей группы не слишком высок. Лишь в Мурманской области и Республике Саха (Якутия) показатели экономического развития выше, чем в среднем по РФ. Доля домашних хозяйств, имеющих широкополосный и мобильный Интернет, выше среднероссийской, а доля пользователей компьютером и Интернетом, напротив, ниже. В регионах четвертой группы выше средней по РФ доля сельского населения со средним специальным образованием. Для пятой группы также получены лишь две регрессионные зависимости, согласно которым самым значимым фактором, влияющим на отказ от использования средств ИКТ для получения государственных услуг, является уровень доходов населения, причем его рост может способствовать увеличению доли отказов. Причина, видимо, кроется в том, что сельскому жителю проще при наличии средств доехать до учреждения по оказанию госуслуг, чем использовать средства ИКТ. Данный вывод подтверждается вхождением в модель параметра удельного веса населения, когда-либо использовавшего сеть Интернет. По-видимому, для этой группы регионов существенным ограничением в использовании онлайн-госуслуг будет являться качество человеческого капитала села. Отсутствие немедленной реакции в качестве доминирующей 
причины отказа может снизить свое значение в регионах пятой группы при росте среднедушевых доходов и затрат на информационные и коммуникационные технологии, а также росте компьютеризации и интернетизации сельских домохозяйств.

\section{Выводы}

Полученные результаты позволяют сделать следующие выводы. Дифференциация регионов РФ по объективным причинам отказа населения от использования средств ИКТ для получения государственных и муниципальных услуг позволяет выделить пять групп регионов со сходными типологическим признаками.

В субъектах РФ, отнесенных к первой, самой неблагополучной по изучаемым параметрам классификационной группе, наблюдается высокий уровень отказов населения от использования государственных услуг в электронном виде по основным причинам, свидетельствующим о серьезной недоработке органов государственной и муниципальной власти по внедрению услуг электронного правительства. Кроме того, в регионах первой группы также имеются проблемы с возможностями использования сельскими домохозяйствами средств ИКТ из-за высокой стоимости подключения и оплаты услуг.

Для регионов второй классификационной группы существенную роль для перевода государственных услуг в электронную форму будут играть затраты государства на ИКТ, а также, как и в регионах первой классификационной группы, рост обеспеченности сельского населения средствами ИКТ. В регионах второй группы одним из серьезных факторов влияния на использование госуслуг в электронном виде является уровень образования населения, степень владения средствами ИКТ.

Для регионов третьей группы, в которых в качестве причин отказа доминирует необходимость нанесения личного визита и предоставления бумажных форм, велико влияние уровня экономического развития региона и величины затрат на информационные и коммуникационные технологии на отказ сельского населения от использования средств Интернета для получения государственных услуг.

В регионах, отнесенных к четвертой классификационной группе, снижению отказов от использования средств ИКТ при получении государственных услуг по объективным причинам будет способствовать развитие инфраструктуры связи, а также рост доступа к широкополосному Интернету сельских домашних хозяйств.

Для пятой группы самым существенным фактором использования средств ИКТ для означенных целей является качество человеческого капитала села. В регионах группы необходимо шире разъяснять населению возможные выгоды от использования средств ИКТ для получения государственных и муниципальных услуг.

Таким образом, проведенное исследование показывает наличие серьезных проблем при применении ИКТ на уровне органов местного самоуправления. Как отмечено в Государственной программе «Цифровая экономика», «лишь 10 \% муниципальных образований отвечают установленным в законодательстве РФ требованиям по уровню цифровизации» [Программа ...].

В основе дифференциации регионов РФ по объективным причинам отказа от использования средств ИКТ при получении государственных услуг лежат различия в уровне развития информационного общества как по линии регионов, так и по линии город - село. Если развитие инфраструктуры ИКТ, а соответственно, доступ домохозяйств к средствам ИКТ определяется в основном уровнем экономического развития региона и уровнем доходов домохозяйств, что характерно для регионов первой-третьей классификационных групп, то при достаточно развитой инфраструктуре происходит усиление роли человеческого капитала в числе факторов, влияющих на объективные причины отказа от использования сети Интернет для получения государственных и муниципальных услуг.

Результаты исследования могут быть использованы для совершенствования государственных механизмов управления развитием и внедрением электронного правительства, координации региональных концепций и программ информатизации, нацеленных, прежде всего на пользователя. 


\section{СПИСОК ЛИТЕРАТУРЫ}

Быков, И. А. «Электронная демократия» vs «Электронное правительство»: Концептуальное противостояние? / И. А. Быков // Политическая экспертиза. - 2005. - № 3. - С. 69-79.

Былина, С. Г. Информатизация агропродовольственного комплекса и сельских территорий России: возможности и ограничения : монография / С. Г. Былина, М. Е. Кадомцева, М. Н. Осовин.Саратов : Саратов. источник. -2018. - 228 с.

Государственная программа Российской Федерации «Информационное общество» (2011-2020 годы). Утверждена Постановлением Правительства Российской Федерации № 313 от 15 апр. 2014 г. - Электрон. текстовые дан. - Режим доступа: http:/government.ru/programs/ 218/events (дата обращения: 21.01.2019). - Загл. с экрана.

Информационное общество: основные характеристики субъектов Российской Федерации : стат. сб. / М. А. Сабельникова [и др.]. - М. : НИУ ВШЭ, 2018.-216 c.

Исследование ООН: электронное правительство 2018. Применение электронного правительства для формирования устойчивого и гибкого общества. - Электрон. текстовые дан. Режим доступа: https://publicadministration. un.org/egovkb/Portals/egovkb/Documents/un/ 2018-Survey/E-Government $\% 20$ Survey $\%$ 202018_Russian.pdf (дата обращения: 03.02.2019). - Загл. с экрана.

Итоги Федерального статистического наблюдения по вопросам использования населением информационных технологий и информационно-телекоммуникационных сетей. - Электрон. текстовые дан. - Режим доступа: http:// www.gks.ru/free_doc/new_site/business/it/ fed nabl-croc/index.html (дата обращения: 10.01.2019). - Загл. с экрана.

Ициксон, А. И. Оценка целесообразности информатизации сельских территорий в условиях цифровой экономики / А. И. Ициксон // Becтник Сибирского государственного университета телекоммуникаций и информатики. 2018. - № 3. - С. 15-22.

Концепция формирования в Российской Федерации электронного правительства до 2010 года. Электрон. текстовые дан. - Режим доступа: http://emag.iis.ru/arc/infosoc/emag.nsf/BPA/ 72b3ea17677bbf2ec325744a00434923 (дата обращения: 05.02.2019). - Загл. с экрана.

Программа «Цифровая экономика Российской Федерации». Утверждена распоряжением Правительства Российской Федерации от 28 июля 2017 г. № 1632-р. - Электрон. текстовые дан. -
Режим доступа: https://government.ru/ rugovclassifier/614/events (дата обращения: 10.01.2019). - Загл. с экрана.

Регионы России. Социально-экономические показатели. 2018 : стат. сб. - М. : Росстат, 2018. - 1162 c.

Российский статистический ежегодник. 2018 : стат. сб. - М. : Росстат, 2018. - 694 с.

Системный проект электронного Правительства Российской Федерации // Минкомсвязи России (2 марта 2016 г.). - Электрон. текстовые дан. - Режим доступа: https:/digital.gov.ru/ uploaded/files/prilozhenie-2protokolzasedaniya-soveta-ri21102016539pr.pdf (дата обращения: 20.02.2019). - Загл. с экрана.

Степанова, А. М. Информационная политика государства по продвижению электронного правительства / А. М. Степанова / Вестник Сиб. ин-та бизнеса и информ. технологий. - 2017. №2 222). - С. 65-73.

Шапошник, С. Б. Цифровая трансформация в регионах России: роль человеческого капитала / С. Б. Шапошник // Информационное общество. - 2017. - № 6. - Электрон. текстовые дан. - Режим доступа: http://emag.iis.ru/arc/ infosoc/emag.nsf/BPA/e 7 a 19677 dac ff7c8442582fe0030ab9a (дата обращения: 20.02.2019). - Загл. с экрана.

Al-Rahbi, Y. Technical Factors Affecting the Adoption Of e-Government / Y. Al-Rahbi, S. Al-Harrasi, S. Al-Wahaibi // Master Thesis, 15ECTS, Lund University. - 2012. - Electronic text data. - Mode of access: https://lup.lub.lu.se/luur/download ?func $=$ downloadFile\&recordOId $=2799432$ \&fileOId=2799445 (date of access: 18.01.2019). Title from screen.

Belanger, F. The Effects of the Digital Divide on EGovernment:An Emperical Evaluation/F. Belanger, L. Carter // Proceedings of the $39^{\text {th }}$ Annual Hawaii International Conference on System Sciences (HICSS'06). - Electronic text data. - Mode of access: https://ieeexplore.ieee.org/document/ 1579452. - Title from screen.

Chatzoglou, P. Factors Affecting the Intention to Use e-Government Services / P. Chatzoglou, D. Chatzoudes, S. Symeonidis // Proceedings of the Federated Conference on Computer Science and Information Systems. - 2015. - P. 1489-1498. DOI: https://doi.org/10.15439/2015F171.

García-Sánchez, I.-M. Determinants of E-Government Development: Some Methodological Issues / I.-M. García-Sánchez, B.Cuadrado-Ballesteros, J.-V.Frías-Aceituno // Journal of Management and Strategy. - 2012. - Vol. 3, № 3. - P. 11-20.

Heeks, R. Most e-Government-for-Development Projects Fail: How Can Risks be Reduced? / R. Heeks // Working Paper Series. - Electronic 
text data. - Mode of access: http://unpan1.un.org/ intradoc/groups/public/documents/NISPAcee/ UNPAN015488.pdf(date of access: 19.01.2019). Title from screen.

\section{REFERENCES}

Bykov A. «Elektronnaya demokratiya» vs «Elektronnoe pravitelstvo»: Kontseptualnoe protivostoyanie? ["E-Democracy" vs. "E-Government": Conceptual Confrontation]. Politicheskaya ekspertiza, 2005, no. 3, pp. 69-79.

Bylina S.G., Kadomtseva M.E., Osovin M.N. Informatizatsiya agroprodovolstvennogo kompleksa $i$ selskikh territoriy Rossii: vozmozhnosti i ogranicheniya: monografiya [Informatization of the Agri-Food Complex and Rural Territories of Russia: Opportunities and Limitations: Monograph]. Saratov, Saratovskiy istochnik Publ., 2018. 228 p

Gosudarstvennaya programma Rossiyskoy Federatsii "Informatsionnoe obshchestvo» (20112020 gody). Utverzhdena Postanovleniem Pravitelstva Rossiyskoy Federatsii № 313 ot 15 apr. 2014 g. [State Program of the Russian Federation "Information society" (2011-2020). Approved by Decree of the Government of the Russian Federation no. 313 of April 15 2014]. URL: http://government.ru/programs/218/ events/ (accessed 21 January 2019).

Sabelnikova M.A., Abdrahmanova G.I., Gohberg L.M., Dudorova O.Yu. et al. Informatsionnoe obshchestvo: osnovnye kharakteristiki subyektov Rossiyskoy Federatsii: stat. sb. [Information Society: Main Characteristics of the Constituent Entities of the Russian Federation. Statistical Compilation]. Moscow, NIU VShE, 2018. 216 p.

Issledovanie OON: elektronnoe pravitelstvo 2018. Primenenie elektronnogo pravitelstva dlya formirovaniya ustoychivogo $i$ gibkogo obshchestva [UN Study: E-Government 2018. Use of E-Government to Create a Sustainable and Flexible Society]. URL: https:// publicadministration.un.org/egovkb/Portals/ egovkb/Documents/un/2018-Survey/Egovernment\%20Survey\%202018_Russian.pdf (accessed 3 February 2019).

Itogi Federalnogo statisticheskogo nablyudeniya po voprosam ispolzovaniya naseleniem informatsionnykh tekhnologiy i informatsionnotelekommunikatsionnykh setey [Results of the Federal Statistical Observation on the Use of Information Technologies by the Population and Information and Telecommunication Networks]. URL: http://www.gks.ru/free_doc/new_site/ business/it/ fed_nabl-croc/index.html (accessed 10 January 2019).

Itsikson A.I. Otsenka tselesoobraznosti informatizatsii selskikh territoriy v usloviyakh tsifrovoy ekonomiki [Evaluation of the Feasibility of Informatization of Rural Areas in a Digital Economy]. Vestnik Sibirskogo gosudarstvennogo universiteta telekommunikatsiy i informatiki [Vestnik SibGUTI], 2018, no. 3, pp. 15-22.

Kontseptsiya formirovaniya $v$ Rossiyskoy Federatsii elektronnogo pravitelstva do 2010 goda [Concept of Forming in the Russian Federation E-Government Until 2010]. URL: http://emag.iis.ru/arc/infosoc/emag.nsf/ BPA/72b3ea17677bbf2ec325744a00434923 (accessed 5 February 2019).

Programma «Tsifrovaya ekonomika Rossiyskoy Federatsii». Utverzhdena rasporyazheniem Pravitelstva Rossiyskoy Federatsii ot 28 iyulya 2017 g. № 1632-r. [Program "Digital Economy of the Russian Federation". Approved by the Order of the Government of the Russian Federation of July 28, 2017, no. 1632-p]. URL: http://government.ru/ rugovclassifier/614/ events/ (accessed 10 January 2019).

Regiony Rossii. Sotsialno-ekonomicheskie pokazateli. 2018: stat. sb. [Regions of Russia. Socio-economic Indicators 2018. Statistical Compilation]. Moscow, Rosstat, 2018. 1162 p. Rossiyskiy statisticheskiy ezhegodnik. 2018: stat. sb. [Russian Statistical Yearbook. 2018. Statistical Compilation]. Moscow, Rosstat, 2018. 694 p.

Sistemnyy proekt elektronnogo Pravitelstva Rossiyskoy Federatsii [System Project of the Electronic Government of the Russian Federation]. Minkomsvyazi Rossii (2 marta 2016 g.) [Ministry of Communications of Russia (March 2, 2016)]. URL: https://digital.gov.ru/ uploaded/files/prilozhenie-2protokolzasedaniya-soveta-ri21102016539pr.pdf. (accessed 20 February 2019).

Stepanova A.M. Informatsionnaya politika gosudarstva po prodvizheniyu elektronnogo pravitelstva [Information Policy of the State to Promote E-Government]. Vestnik Sib. in-ta biznesa i inform. tekhnologiy [Herald of Siberian Institute of Business and Information Technologies], 2017, no. 2 (22), pp. 65-73.

Shaposhnik S.B. Tsifrovaya transformatsiya $\mathrm{v}$ regionakh Rossii: rol chelovecheskogo kapitala [Digital Transformation in the Regions of Russia: The Role of Human Capital]. Informatsionnoe obshchestvo [Information Society], 2017, no. 6. URL: http://emag.iis.ru/arc/infosoc/emag.nsf/ BPA/e7a 19677dacff7c8442582fe0030ab9a (accessed 20 February 2019). 


\section{РЕГИОНАЛЬНАЯ ЭКОНОМИКА}

Al-Rahbi Y., Al-Harrasi S., Al-Wahaibi S. Technical Factors Affecting the Adoption OfE-Government. Master Thesis, 15ECTS, Lund University, 2012. URL: https://lup.lub.lu.se/luur/download?func= downloadFile\&recordOId=2799432\&fileOId $=2799445$ (accessed 18 January 2019).

Belanger, F. Carter L. The Effects of the Digital Divide on E-Government: An Emperical Evaluation. Proceedings of the $39^{\text {th }}$ Annual Hawaii International Conference on System Sciences (HICSS'06). URL: https://ieeexplore.ieee.org/ document/1579452.

Chatzoglou P., Chatzoudes D., Symeonidis S. Factors Affecting the Intention to Use Ee-Government
Services. Proceedings of the Federated Conference on Computer Science and Information Systems, 2015, pp. 1489-1498. DOI: https://doi.org/10.15439/2015F171.

García-Sánchez I.-M., Cuadrado-Ballesteros B., FríasAceituno J.-V. Determinants of E-Government Development: Some Methodological Issues. Journal of Management and Strategy, 2012, vol. 3, no. 3, pp. 11-20.

Heeks R. Most e-Government-for-Development Projects Fail: How Can Risks be Reduced? Working Paper Series. URL: http://unpan1.un.org/intradoc/ groups/public/documents/NISPAcee/UNPAN 015488.pdf(accessed 19 January 2019).

\section{Information About the Author}

Svetlana G. Bylina, Candidate of Sciences (Economics), Senior Researcher, Institute of Agrarian Problems of the Russian Academy of Sciences, Moskovskaya St., 94, 410012 Saratov, Russian Federation, svbylina@rambler.ru, https://orcid.org/0000-0002-5179-7721

\section{Информация об авторе}

Светлана Геннадиевна Былина, кандидат экономических наук, старший научный сотрудник, Институт аграрных проблем РАН, ул. Московская, 94, 410012 г. Саратов, Российская Федерация, svbylina@rambler.ru, https://orcid.org/0000-0002-5179-7721 